BMJ Open

Sport \&

Exercise

Medicine

\title{
Adaptation, translation and reliability of the Australian 'Juniors Enjoying Cricket Safely' injury risk perception questionnaire for Sri Lanka
}

\author{
Prasanna J Gamage, ${ }^{1,2}$ Lauren V Fortington, ${ }^{1}$ Caroline F Finch ${ }^{1}$
}

\begin{abstract}
To cite: Gamage PJ, Fortington LV, Finch CF. Adaptation, translation and reliability of the Australian 'Juniors Enjoying Cricket Safely' injury risk perception questionnaire for Sri Lanka. BMJ Open Sport \& Exercise Medicine 2018;4:e000289. doi:10.1136/ bmjsem-2017-000289
\end{abstract}

- Additional material is published online only. To view, please visit the journal online (http://dx.doi.org/10.1136/ bmjsem-2017-000289).

Accepted 27 November 2017

Check for updates

${ }^{1}$ Australian Centre for Research into Injury in Sport and its Prevention (ACRISP), Federation University Australia, Ballarat, Victoria, Australia

${ }^{2}$ School of Health Science and Psychology, Faculty of Health, Federation University Australia, Ballarat, Victoria, Australia

Correspondence to Dr Prasanna J Gamage; janakagamage@students. federation.edu.au

\section{ABSTRACT}

Objectives Cricket is a very popular sport in Sri Lanka. In this setting there has been limited research; specifically, there is little knowledge of cricket injuries. To support future research possibilities, the aim of this study was to cross-culturally adapt, translate and test the reliability of an Australian-developed questionnaire for the Sri Lankan context.

Methods The Australian 'Juniors Enjoying Cricket Safely' (JECS-Aus) injury risk perception questionnaire was cross-culturally adapted to suit the Sri Lankan context and subsequently translated into the two main languages (Sinhala and Tamil) based on standard forward-back translation. The translated questionnaires were examined for content validity by two language schoolteachers. The questionnaires were completed twice, 2 weeks apart, by two groups of school cricketers (males) aged 11-15 years (Sinhala $(n=24)$, Tamil $(n=30))$ to assess reliability. Test-retest scores were evaluated for agreement. Where responses were $<100 \%$ agreement, Cohen's kappa $(\kappa)$ statistics were calculated. Questions with moderate-topoor test-retest reliability $(\kappa<0.6)$ were reconsidered for modification.

Results Both the Sinhala and Tamil questionnaires had $100 \%$ agreement for questions on demographic data, and $88 \%-100 \%$ agreement for questions on participation in cricket and injury history. Of the injury risk perception questions, $72 \%$ (Sinhala) and 90\% (Tamil) questions showed a substantial $(\kappa=0.61-0.8)$ and almost perfect $(\kappa=0.81-1.0)$ test-retest agreement.

Conclusion The adapted and translated JECS-SL questionnaire demonstrated strong reliability. This is the first study to adapt the JECS-Aus questionnaire for use in a different population, providing an outcome measure for assessing injury risk perceptions in Sri Lankan junior cricketers.

\section{INTRODUCTION}

Preventing sports-related injuries among athletes is important to the health and safety of participants. Consequently, sporting governing bodies have focused research on better understanding injury and injury risk among those who partake in their respective sports. ${ }^{12}$ Injuries among junior athletes are a major public health burden and consequently,

\section{What are the new findings?}

- This study successfully produced reliable Sinhala and Tamil versions of the Juniors Enjoying Cricket Safely injury risk perception questionnaires that can be administered to Sri Lankan junior cricketers.

- In reliability assessment, the questions relating to injury risk perceptions in specific cricket-playing tasks required the most modifications due to low agreement.

- This study provides a successful process for the adaptation, translation and testing of an Englishlanguage outcome measure in sports injury for use in different contexts.

preventing injures has become a priority. ${ }^{34}$ One strategy is injury risk perceptions recognition and subsequent implementation of measures that serve to moderate negative perceptions or promote positive perceptions. ${ }^{4}$

The Juniors Enjoying Cricket Safely (JECS) study was an Australian project developed to identify injuries and injury risk perceptions associated with playing cricket at a junior level. ${ }^{56}$ The main objective of that project was to collect information to inform the development of injury prevention strategies and encourage safe sports participation. In order to achieve this objective, the JECS participant baseline questionnaire (JECS-Aus) was developed as the study instrument to collect information about injuries and injury risk perceptions in junior cricketers. The JECS-Aus questionnaire was validated and subsequently used among Australian junior cricketers, aged 8-16 years, to examine their injury risk perceptions in playing cricket. $^{78}$ The findings of the JECS-Aus study highlighted the importance of recognising the risk perception behaviours and attitudes among junior cricketers, providing an incentive to evaluate injury risk perceptions among junior cricketers in other cricket-playing nations. 
Cricket is a field-based team sport, played mainly by the member countries of the Commonwealth. ${ }^{9}$ It is a very popular sport among juniors, especially among the Indian subcontinent cricket-playing nations of Bangladesh, India, Pakistan and Sri Lanka. Cricket is, without doubt, the most popular sport in Sri Lanka. ${ }^{10}$ More than 15000 school players take part in school cricket at competitive level, approximately competing over 3000 matches in each cricket season annually. ${ }^{11}{ }^{12}$ Despite the high participation by juniors, knowledge about cricket injuries, injury mechanisms and participants' risks perceptions is lacking. To date, neither injuries nor injury risk perceptions have been investigated among Sri Lankan junior cricketers. Consequently, there is now a recognised need to conduct research among junior cricketers in these subcontinent countries including Sri Lanka.

At present, JECS-Aus is the only tool available to evaluate injury risk perceptions in junior cricket. It was developed in English and is yet to be translated into other languages common to other cricketing nations. There is strong potential for the JECS-Aus injury risk perception questionnaire to serve as a validated tool to evaluate injury risk perceptions among Sri Lankan junior cricketers. Once adapted to the Sri Lankan context and translated into two main languages (Sinhala and Tamil), this could gather injury risk perception data from a socioeconomically and culturally different cricket population. Therefore, the primary objective of this study was to cross-culturally adapt, translate and test content validity and reliability of an existing questionnaire (JECS-Aus) for use among Sri Lankan junior cricketers.

\section{METHODS}

The original English version of the JECS-Aus questionnaire consisted of several domains: participation in cricket, training and competition workload, other sports participation, sports injury history, safety in cricket with injury risk perception. ${ }^{7}$ In the present study, the JECS-Aus questionnaire was cross-culturally adapted, translated and evaluated for content validity and reliability in a stepwise manner, following guidelines used commonly within the health science literature as explained in figure $1 .^{13}$

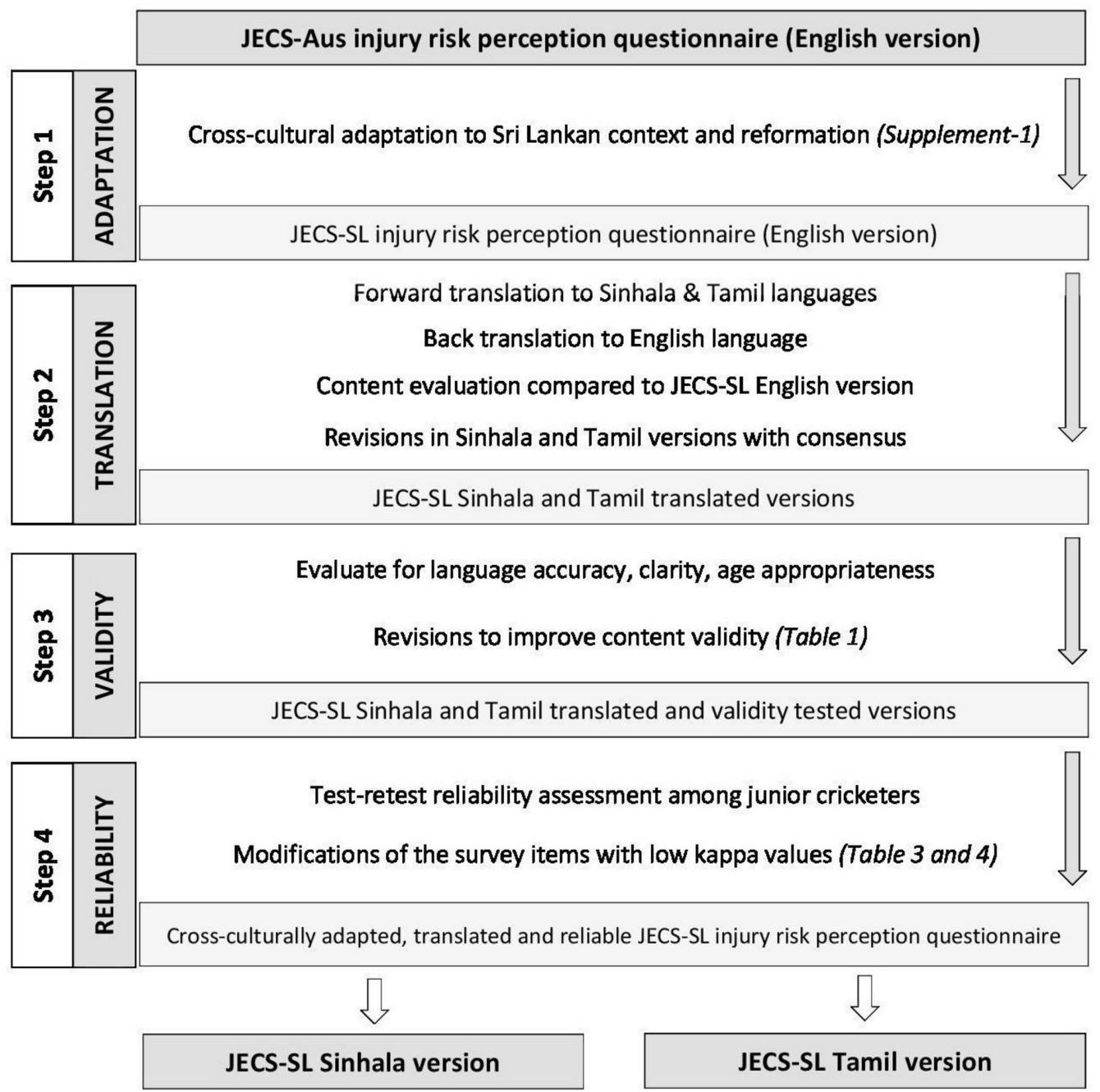

Figure 1 Stepwise process of developing Juniors Enjoying Cricket Safely (JECS)-SL Sinhala and Tamil versions of the injury risk perception questionnaire. 


\section{Step 1: cross-cultural adaptation and reformation}

The JECS-Aus questionnaire was first adapted to suit the Sri Lankan context and conditions. The objective of cross-cultural adaptation was to ensure that the content of the questionnaire is relevant to the social, cultural and environmental settings in Sri Lanka. For example, some of the sports and recreational activities stated in the JECS-Aus questionnaire are not commonly seen in the Sri Lanka society and sports culture (eg, skateboarding, playing on the trampoline, Australian rules football). Therefore, these sports had to be removed and replaced with the local sports (eg, elle), in order to make the content comprehensible to the Sri Lankan junior cricketers. These modifications were made following discussion, with full agreement by the members of the research team, which includes two researchers from Australia (CFF, LVF) and a third from Sri Lanka (PJG).

\section{Step 2: translation from English to Sinhala and Tamil languages}

The JECS-SL questionnaire was translated from English into Sinhala and Tamil languages (the two main languages in Sri Lanka) according to standard forward-back translation guidelines. ${ }^{14}$ Two accredited translators, bilingual in English-Sinhala and EnglishTamil languages, translated the English version to Sinhala and Tamil languages, respectively (forward translation). The translated versions were then back-translated into English by two final-year medical students bilingual in English-Tamil or English-Sinhala languages. The students were completely blind to the English version of the JECS-SL questionnaire. The back-translated English versions were compared with the original English version of JECS-SL, and areas with discrepancies and doubts were identified by two members of the research team independently (LVF, PJG). The two final-year medical students (who did the back translation) revised the Sinhala and Tamil translated versions addressing the issues identified by the two reviewers. Additions and deletions were made accordingly by the lead author (PJG) after discussion with the two medical students until agreement was reached.

\section{Step 3: testing for content validity}

The translated Sinhala and Tamil versions of the JECS-SL questionnaires were examined by two Sinhala and Tamil language schoolteachers to ascertain the language accuracy (grammar and spelling mistakes), clarity and age-appropriateness in the target population. The questionnaires were developed to be completed by junior cricketers in under-13 and under-15 age categories in Sri Lanka (age range from 11 to 15 years). Based on their comments, relevant questions were refined again to obtain a version of the JECS-SL Sinhala and Tamil questionnaires with content validity.

\section{Step 4: testing for reliability}

The JECS-SL questionnaires were then tested among a group of junior cricketers (males) to examine reliability using the test-retest method. Two junior cricket teams representing the under-13 age group from a Sinhala language-based $(n=24)$ and a Tamil languagebased school $(n=30)$ were selected from Western and Northern provinces, respectively. The questionnaire was administered twice among the players during the 2016 school cricket season. Test 1 was carried out in the presence of the lead author (PJG), to clarify any questions with understanding during the test. Test 2 was conducted after 2 weeks by the schoolteachers in charge of the teams, with completed questionnaires subsequently returned to the research team in a sealed envelope.

\section{Statistical analysis}

For the test-retest reliability assessment, response data were entered into an excel data sheet and a direct comparison was made between test 1 and test 2 responses to examine the percentage agreement. Questions that did not achieve $100 \%$ agreement underwent the test-retest assessment. The questionnaire response items were categorical variables and therefore, Cohen's kappa ( $\kappa$ ) was used to measure the consistency and agreement between the two tests. ${ }^{15}$ 'Do not know' and 'missing' responses were removed before conducting the reliability assessment, and a weighted kappa $\left(\mathrm{\kappa w}^{2}\right)$ statistic was used for ordinal items (questions with Likert scale responses). Observer agreement was graded according to the Landis and Koch grading system. ${ }^{16}$ Questions with moderate-to-poor test -retest reliability $(\kappa<0.6)$ were considered for modification in a revised JECS-SL. Statistical analysis was performed using SPSS V.24 (IBM, Armonk, New York, USA). Approval from the school cricket authorities of the selected schools and informed written consent from parents and participants were obtained before all survey administrations.

\section{RESULTS}

\section{Cross-cultural adaptation}

All modifications made during the cross-cultural adaptation process are presented in online supplementary file 1. Following cross-cultural adaptation to the Sri Lankan context, the new questionnaire (JECS-SL) consisted of 23 questions across three domains: (1) participation in cricket (4 questions), (2) injury history (9 questions) and (3) safety and injury risk perceptions (10 questions).

\section{Translation}

Evaluation of the back-translated English version by the two members of the research team identified 16 questions in the Sinhala questionnaire and 13 in the Tamil questionnaire that showed discrepancies when compared with the original English version. The words and phrases used in these questions provided a different meaning or were incorrectly interpreted. In addition, two responses 
Table 1 Summary of the modifications made during the content validity assessment to improve clarity of the translated Juniors Enjoying Cricket Safely (JECS)-SL

\begin{tabular}{|c|c|c|}
\hline Items modified & Modification description & Modification made \\
\hline 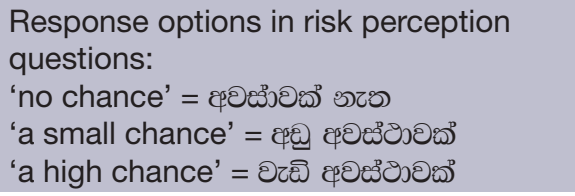 & $\begin{array}{l}\text { Rephrase to a simple and everyday use } \\
\text { Sinhala terms to improve clarity }\end{array}$ & 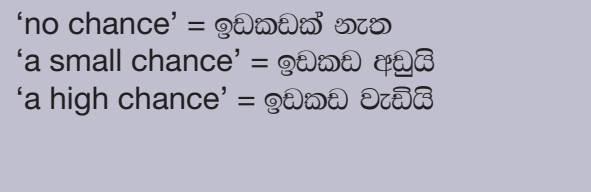 \\
\hline 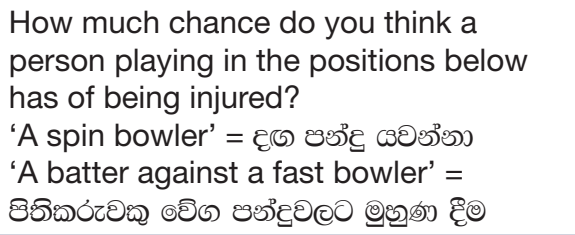 & $\begin{array}{l}\text { The Sinhala phrase 'to sustain an injury' } \\
\text { was added to the responses in order to } \\
\text { understand them clearly. This change was } \\
\text { made in all items in this section }\end{array}$ & 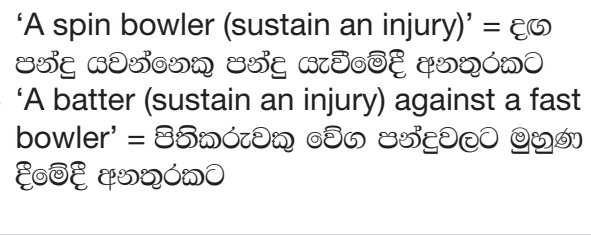 \\
\hline 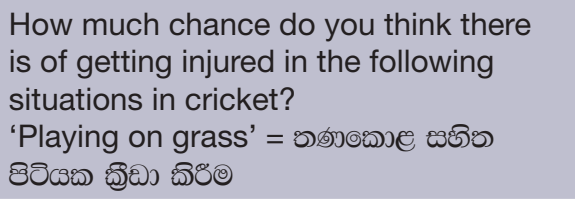 & $\begin{array}{l}\text { The Sinhala terms 'to sustain an injury' } \\
\text { was added to understand the responses } \\
\text { clearly. This change was made in all items } \\
\text { in this section }\end{array}$ & 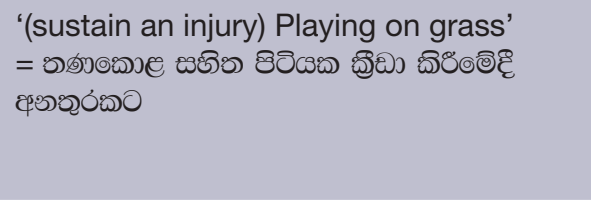 \\
\hline 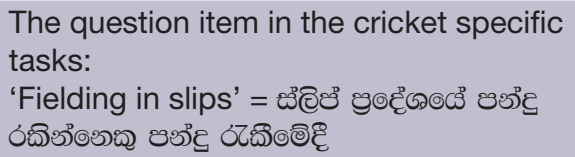 & $\begin{array}{l}\text { The term 'slip' is used as the same } \\
\text { manner in Sinhala language in describing } \\
\text { slip fielding position in cricket, and } \\
\text { therefore it was kept as 'slip' fielder }\end{array}$ & 'slips' = జెర్రితె \\
\hline
\end{tabular}

with words and phrases that were difficult to translate with language accuracy were identified (eg, slip fielder, boundary line). For example, there is no specific Sinhala or Tamil word for the English word 'slip' and therefore, the same word was written in the Sinhala and Tamil questionnaires using the respective languages.

\section{Content validity}

The translated JECS-SL questionnaires were examined for language accuracy, clarity and age appropriateness. Twelve questions in the Sinhala questionnaire and seven questions in the Tamil questionnaire had grammar and spelling errors that were highlighted by the two schoolteachers who examined them, and changes were made accordingly. Eight questions were identified as not being clear enough to junior participants. The lead author (PJG) discussed these questions with the two schoolteachers and the question items were modified to improve their clarity. A summary of these modifications is presented in table 1 . Both teachers agreed that the length of the survey and the format of the questions were appropriate to children aged 11 years and above.

\section{Test-retest reliability}

Percentage agreement and test-retest reliability scores for all questions for both Sinhala and Tamil JECS-SL questionnaires are provided in online supplementary file 2. The question responses related to the section of 'injury risk perceptions of cricket-specific tasks' reported the highest number of items with low kappa values. Percentage (\%) agreement and test-retest reliability measures (weighted kappa values) of the items in this section is presented in table 2. Modifications to the survey questions with low kappa values $(<0.6)$ were made after discussion with the two schoolteachers (who had earlier revised for content validity). Tables 3 and 4 provide a summary of modifications to the survey items with low kappa values $(<0.6)$ in the Sinhala version and Tamil version of the JECS-SL questionnaires, respectively.

Demographic data, participation in cricket, sports injury history In test-retest reliability assessment, questions relating to demographic data (age, gender, family members) showed $100 \%$ agreement in both Sinhala and Tamil questionnaires. Questions in the section "participation in cricket' showed $96 \%-100 \%$ agreement in the Sinhala questionnaire and $93 \%-97 \%$ agreement in the Tamil questionnaire. In this section, only one question, 'how much do you like playing cricket?' obtained a low kappa values (0.65 in Sinhala and 0.48 in Tamil; table 4). Similarly, high test-retest agreement was noted in the questions about the 'sports injury history' section (92\%-100\% in Sinhala and 88\%-100\% in Tamil). However, two questions in the Tamil questionnaire showed a low kappa values in this section ( $\kappa$ range $=0.45-0.49$; table 4 ). 
Table 2 Percentage (\%) agreement and test-retest reliability scores (weighted kappa values) of survey questions in 'injury risk perceptions of cricket-specific tasks' section

\begin{tabular}{|c|c|c|c|c|c|c|}
\hline \multirow{2}{*}{$\begin{array}{l}\text { Question item } \\
\text { How much chance do you think a person } \\
\text { playing in the positions below has ofbeing } \\
\text { injured? }\end{array}$} & \multicolumn{3}{|c|}{ Sinhala questionnaire $(n=24)$} & \multicolumn{3}{|c|}{ Tamil questionnaire $(n=30)$} \\
\hline & $\%$ agreement & $\begin{array}{l}\text { Kappa } \\
\text { value* }\end{array}$ & $\begin{array}{l}\text { Level of } \\
\text { reliabilityt }\end{array}$ & $\%$ agreement & $\begin{array}{l}\text { Kappa } \\
\text { value*}^{*}\end{array}$ & $\begin{array}{l}\text { Level of } \\
\text { reliability }\end{array}$ \\
\hline A fast bowler or medium pace bowler & 75 & 0.60 & Moderate & 93.3 & 0.82 & Almost perfect \\
\hline A spin bowler & 95.8 & 0.87 & $\begin{array}{l}\text { Almost } \\
\text { perfect }\end{array}$ & 86.7 & 0.78 & Substantial \\
\hline $\begin{array}{l}\text { A wicket keeper wearing a helmet while } \\
\text { wicket keeping facing a spin bowler }\end{array}$ & 79.2 & 0.65 & Substantial & 83.3 & 0.8 & Substantial \\
\hline $\begin{array}{l}\text { A wicket keeper is not wearing a helmet } \\
\text { while wicket keeping facing a spin } \\
\text { bowler }\end{array}$ & 79.2 & 0.32 & Fair & 80 & 0.7 & Substantial \\
\hline $\begin{array}{l}\text { A wicket keeper wearing a helmet while } \\
\text { wicket keeping facing a fast bowler }\end{array}$ & 91.7 & 0.48 & Moderate & 90 & 0.9 & Almost perfect \\
\hline $\begin{array}{l}\text { A wicket keeper is not wearing a helmet } \\
\text { while wicket keeping facing a fast bowler }\end{array}$ & 79.2 & 0.64 & Substantial & 76.7 & 0.65 & Substantial \\
\hline A batter against a spin bowler & 83.3 & 0.70 & Substantial & 93.3 & 0.93 & Almost perfect \\
\hline A batter against a fast bowler & 87.5 & 0.76 & Substantial & 86.2 & 0.83 & Almost perfect \\
\hline A batter running between wickets & 79.2 & 0.75 & Substantial & 76.7 & 0.56 & Moderate \\
\hline Fielding in the outfield (at boundary line) & 83.3 & 0.59 & Moderate & 72.4 & 0.60 & Moderate \\
\hline Fielding in the infield (at 30 yard circle) & 87.5 & 0.82 & $\begin{array}{l}\text { Almost } \\
\text { perfect }\end{array}$ & 75.9 & 0.59 & Moderate \\
\hline $\begin{array}{l}\text { Fielding in close to a batter (within } 15 \\
\text { yards) }\end{array}$ & 83.3 & 0.39 & Fair & 86.7 & 0.80 & Substantial \\
\hline Fielding in slips & 79.2 & 0.64 & Substantial & 83.3 & 0.81 & Almost perfect \\
\hline
\end{tabular}

*Weighted kappa values.

†Based on Landis and Koch grading system.

Safety and injury risk perception

Overall, no survey questions related to 'safety and injury risk perceptions' recorded a kappa value of $\leq 0.2$ (slight agreement), and therefore no questions were deleted. The questions with a kappa value between 0.21 and 0.4 (fair agreement) underwent some wording modifications. These include two question responses (question $17)$ in the Sinhala questionnaire related to 'injury risk perceptions of cricket-specific tasks' $(\kappa$ range $=0.32$ 0.39 ; table 3 ). The questions with kappa values between 0.41 and 0.6 (moderate agreement) also underwent minor modifications. This included three questions in Sinhala ( $\kappa$ range $=0.48-0.6$; questions $15,17,19$; table 3 ) and three question responses in Tamil $(\kappa$ range $=0.56-$ 0.6 ; question 17; table 4). One question in the Sinhala questionnaire related to 'injury risk associated with different ground conditions' showed a moderate agreement ( $\kappa=0.45$; 'playing on hard ground, mainly dirt, not much grass'), and was modified accordingly (table 3). The questions that reported a higher kappa value of 0.61-0.8 (substantial agreement) and 0.81-0.99 (almost perfect agreement) were reviewed. Of the injury risk perception questions, 72\% (Sinhala) and 90\% (Tamil) questions showed a substantial $(\kappa=0.61-0.8)$ and almost perfect $(\kappa=0.81-1.0)$ test-retest agreement. To support consistency across the questionnaire, where a commonly used phrase was changed in an item with low kappa scores, the same phrase was also modified in questions which otherwise had good agreement (eg, two wicket keeping scenarios with low kappa values of $<0.6$ were modified to understand them better, and the same modifications were made in the other two wicket keeping scenarios with kappa values $>0.6$; table 3 ).

\section{DISCUSSION}

This study has produced cross-culturally adapted Sinhala and Tamil translated versions of the JECS injury risk perception questionnaire for use with Sri Lankan junior cricketers (ie, the JECS-SL). This is the first time that the JECS-Aus questionnaire has been translated into languages other than English for use outside Australia. Having a common study instrument, which can be transformed into different social, cultural and environmental contexts, is important, as it enables data to be collected from different athlete populations on a common theme that can be compared across different nations. For cricket, this has the potential to have a large impact as most of the countries are multilinguistic and have main languages other than English. 


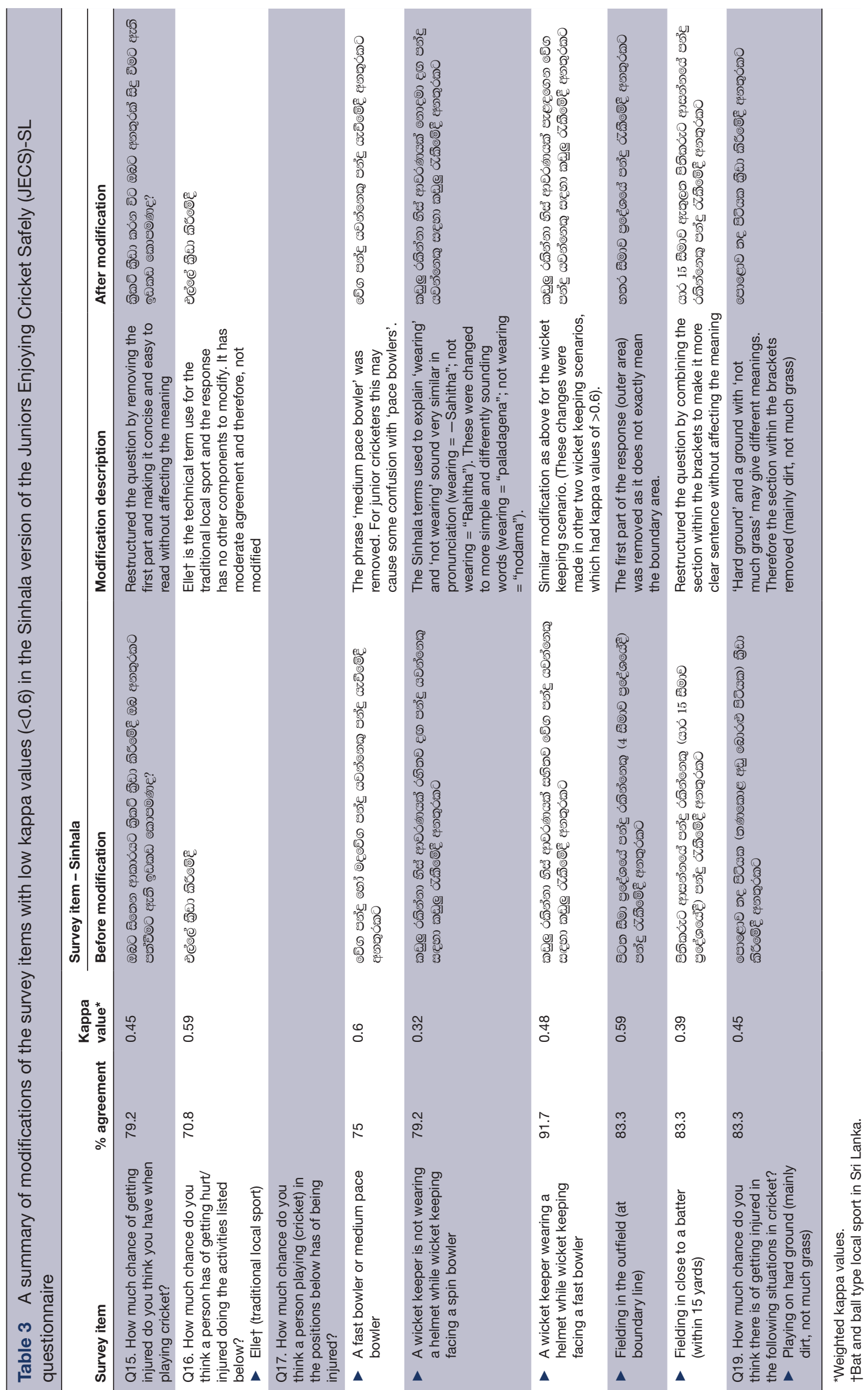




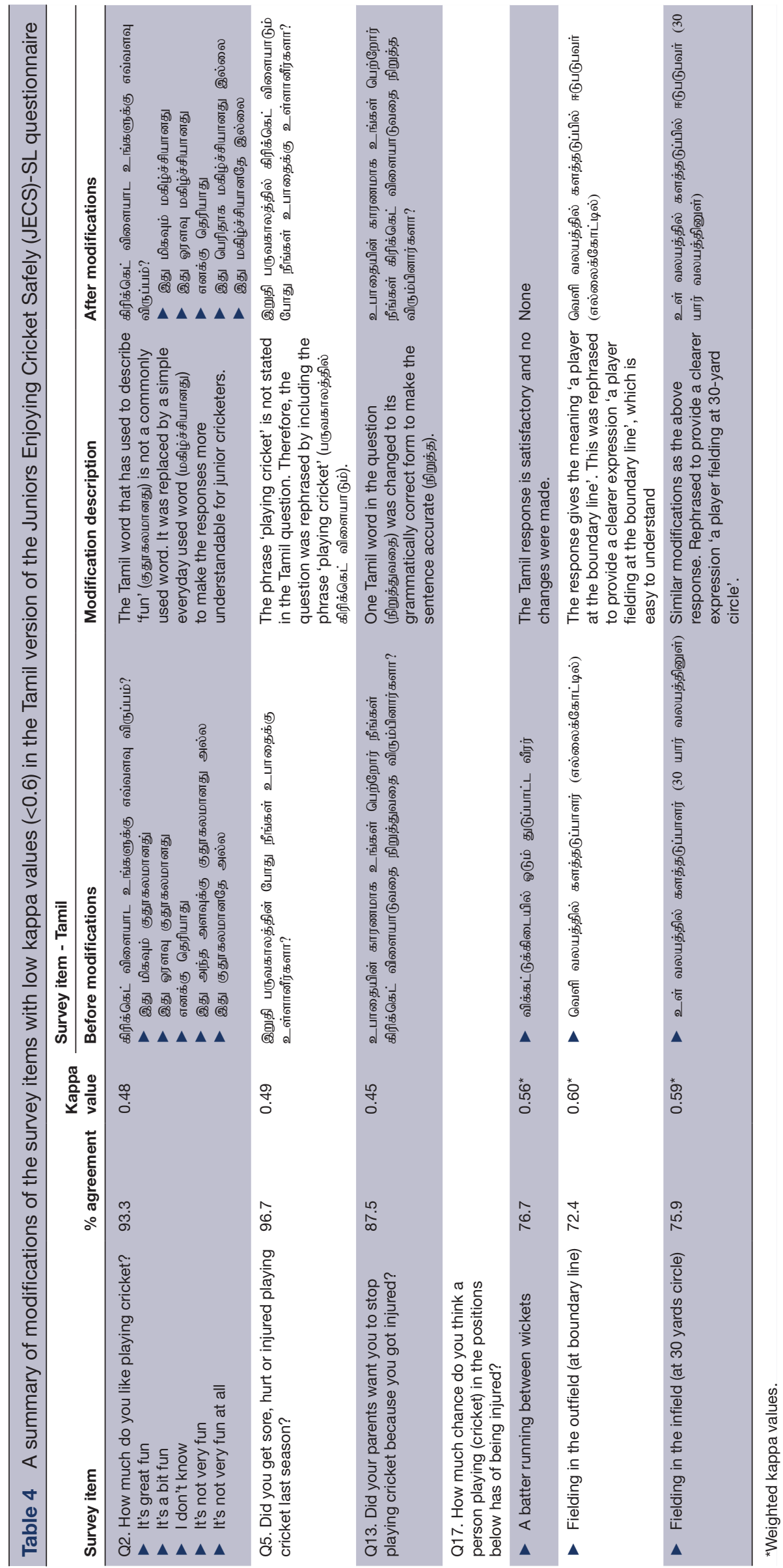




\section{Psychometric evaluation and properties}

Psychometric evaluation of the JECS-SL questionnaires was carried out through a test-retest reliability assessment. The original JECS-Aus questionnaire had undergone a similar reliability assessment through the test-retest method. ${ }^{7}$ Overall, kappa values for the different sections of the JECS-SL questionnaires were greater than those reported for JECS-Aus questionnaire. ${ }^{7}$ Test-retest agreement for questions related to injury risk perceptions of cricket-specific tasks' of the JECS-Aus questionnaire ranged from 0.22 to 0.6 , with $78 \%$ of the questions, reaching fair to moderate level of agreement. In contrast, the JECS-SL questionnaires had a lower number of questions $(38 \%$ in the Sinhala version and $23 \%$ in the Tamil version) with a kappa value of $\leq 0.6$. This suggests the newly developed JECS-SL questionnaires are equally reliable tools that can be used among junior cricketers in Sri Lanka.

The questions that underwent modifications in JECS-SL questionnaires with low kappa values $(\kappa \leq 0.6)$ were mainly from the section relating to injury risk perceptions of cricket-specific tasks'. One possible explanation for the lower agreement for these questions in the JECS-SL could be the complexity of the questions explaining similar cricket-playing tasks with subtle variations. For example, the risk of getting injured during wicket keeping tasks was assessed under four different situations depending on the type of bowler (spin bowler vs fast bowler) and the standing position of the wicket keeper (close to the wicket vs away from the wicket). These questions were modified in the final versions of JECS-SL, by refining the wording to improve clarity after discussion with the language schoolteachers. Nevertheless, the identical questions of the JECS-Aus questionnaire showed lower kappa values (mostly with fair and moderate agreement) than the JECS-SL questionnaires.

\section{Contribution and impact on regional test-cricket playing nations}

Compared with other test-cricket playing nations such as Australia, England and South Africa, there is an apparent deficiency of cricket-related literature from Sri Lanka and other South Asian cricket-playing nations. In this context, adapting the research methods and related resources (eg, survey questionnaires) from already published literature is an essential step to generate comparative high-quality data from the South Asian region. The language barrier is one drawback in having limited access to English language literature, as the main languages of all four test-cricket playing nations in South Asia (Bangladesh, India, Pakistan and Sri Lanka) are non-English and often multilanguage. Therefore, this study delivers a worthy illustration to other South Asian test-cricket playing nations, where the JECS-Aus questionnaire and other sports outcome measures or similar resources can be adapted and translated. ${ }^{17}{ }^{18}$ Such attempts in the future will support the expansion of scientific contributions and knowledge from cricketers and sports participants in South Asia.
The way forward: implementing the new JECS-SL questionnaires into practice

Evaluating how athletes perceive injury risks during sports participation is an important research approach for injury prevention in sports science and sports medicine literature. ${ }^{19-22}$ Identifying injury risks and injury risk perceptions among junior athletes is important to minimise the injury burden and develop preventive measures. ${ }^{23}$ Recognising the different risk perceptions and risk-taking behaviours will enable the development of preventive strategies that challenge and modify negative behaviours and attitudes of athletes, while promoting positive perceptions. ${ }^{24}$ Currently, knowledge about injury risk perceptions in junior cricket is limited to the study conducted by White et al among Australian junior cricketers, but this provides a comparative population for Sri Lankan studies. As examples, there could be differences resulting from knowledge of injury risks, lack of injury prevention resources and often-substandard playing conditions in Sri Lanka. It is likely that injury risk perceptions among Sri Lankan junior cricketers could be influenced and affected by these different factors and therefore, could be different to what is already known from Australian junior cricketers, and worth identifying. The newly developed JECS-SL questionnaires now can be used for this purpose.

\section{Limitations}

Instead of a standard two-person translation, the JECS-SL questionnaires (Sinhala and Tamil versions) were translated by a single translator each for forward and back translation. In order to assure content validity of the questionnaire, the original JECS-Aus questionnaire was reviewed by the experts of the state and national cricket bodies, examining the sport-specific content and relevance of the questions. The JECS-SL questionnaires were only reviewed by the language schoolteachers, mainly to evaluate language and appropriate reading level, but did not undergo additional assessment of the sport-specific relevance of the items as it was assumed that this was well covered in the JECS-Aus. The process of cross-cultural adaptation and translation was carried out following the major steps described by Beaton et $\mathrm{l}^{13}$ (eg, translation, back translation, expert review). However, some of the minor steps (eg, two translations) and their order (eg, synthesis) were slightly changed to suit the present study as illustrated in figure 1.

\section{CONCLUSIONS}

This paper describes the process of cross-cultural adaptation, translation to Sinhala and Tamil languages and reliability testing of the English version of the JECS-AUS injury risk perception questionnaire. Both the Sinhala and Tamil versions of the questionnaire had substantial to almost perfect agreement in the test-retest assessment for the majority of survey items, suggesting a strong reliability. Reliable and accurate questionnaires are useful resources for all cricket-playing nations, especially for 
South Asian cricket-playing countries, where these can be adapted and translated into their context and languages. The newly developed JECS-SL questionnaires now can be used among junior cricketers aged 11-15 years in Sri Lanka to assess injury risk perceptions when playing cricket.

Acknowledgements The authors would like to thank the junior cricketers who took part in the test-retest assessment.

Contributors PJG was supported by an Australian Government Research Training Program (RTP) stipend and RTP Fee-Offset Scholarship through Federation University Australia. ACRISP is one of the International Research Centres for the Prevention of Injury and Protection of Athlete Health supported by the International Olympic Committee (IOC).

Funding This study was supported by Federation University Australia and Australian Government Research Training Program.

Competing interests None declared.

Ethics approval This study was approved by the Human Ethical Review Committee of the Federation University Australia (A16-039).

Provenance and peer review Not commissioned; externally peer reviewed.

Open Access This is an Open Access article distributed in accordance with the Creative Commons Attribution Non Commercial (CC BY-NC 4.0) license, which permits others to distribute, remix, adapt, build upon this work non-commercially, and license their derivative works on different terms, provided the original work is properly cited and the use is non-commercial. See: http://creativecommons.org/ licenses/by-nc/4.0/

(C) Article author(s) (or their employer(s) unless otherwise stated in the text of the article) 2018. All rights reserved. No commercial use is permitted unless otherwise expressly granted.

\section{REFERENCES}

1. Finch CF, Talpey S, Bradshaw A, et al. Research priorities of international sporting federations and the IOC research centres. BMJ Open Sport Exerc Med 2016;2:e000168.

2. Engebretsen L, Bahr R, Cook JL, et al. The IOC Centres of Excellence bring prevention to sports medicine. Br J Sports Med 2014;48:1270-5.

3. Maffulli N, Longo UG, Spiezia F, et al. Aetiology and prevention of injuries in elite young athletes. Med Sport Sci 2011;56:187-200.

4. Frisch A, Croisier JL, Urhausen A, et al. Injuries, risk factors and prevention initiatives in youth sport. Br Med Bull 2009;92:95-121.

5. Finch CF, White P, Dennis R, et al. Fielders and batters are injured too: a prospective cohort study of injuries in junior club cricket. J Sci Med Sport 2010;13:489-95.
6. Twomey DM, White PE, Finch CF. Injury risk associated with ground hardness in junior cricket. J Sci Med Sport 2012;15:110-5.

7. Siesmaa EJ, Blitvich JD, White PE, et al. Measuring children's self-reported sport participation, risk perception and injury history: development and validation of a survey instrument. J Sci Med Sport 2011;14:22-6.

8. White PE, Finch CF, Dennis R, et al. Understanding perceptions of injury risk associated with playing junior cricket. J Sci Med Sport 2011:14:115-20.

9. Perkin $\mathrm{H}$. Teaching the nations how to play: sport and society in the British empire and commonwealth. Int J Hist Sport 1989;6:145-55.

10. Schulenkorf N. Sport events and ethnic reconciliation: attempting to create social change between sinhalese, tamil and muslim sportspeople in war-torn Sri Lanka. Int Rev Sociol Sport 2010;45:273-94.

11. Sri Lanka School Cricket Association. Rules and playing conditions, 2016. Colombo, Sri Lanka: Sri Lanka School Cricket Association, 2016.

12. School cricket 2017. http://www.batsman.com/School_Cricket.aspx (accessed Jun 2017).

13. Beaton DE, Bombardier C, Guillemin F, et al. Guidelines for the process of cross-cultural adaptation of self-report measures. Spine 2000;25:3186-91.

14. Wang WL, Lee HL, Fetzer SJ. Challenges and strategies of instrument translation. West J Nurs Res 2006;28:310-21.

15. Tang W, Hu J, Zhang H, et al. Kappa coefficient: a popular measure of rater agreement. Shanghai Arch Psychiatry 2015;27:62-7.

16. Landis JR, Koch GG. The measurement of observer agreement for categorical data. Biometrics 1977;33:159-74.

17. Senaratna BC, Perera H, Fonseka P. Sinhala translation of child behaviour checklist: validity and reliability. Ceylon Med $J$ 2008:53:40-4.

18. Jayasekara H, Rajapaksa LC, Aaronson NK. Health-related quality-of-life in patients with head-and-neck cancer in Sri Lanka: psychometric properties of the 'Sinhala' version of the EORTC QLQH\&N35. Psychooncology 2009;18:1116-21.

19. Spörri J, Kröll J, Amesberger G, et al. Perceived key injury risk factors in World Cup alpine ski racing--an explorative qualitative study with expert stakeholders. Br J Sports Med 2012;46:1059-64.

20. Finch C, Donohue S, Garnham A. Safety attitudes and beliefs of junior Australian football players. Inj Prev 2002;8:151-4.

21. Strotmeyer S, Lystad RP. Perception of injury risk among amateur Muay Thai fighters. Inj Epidemiol 2017;4:2.

22. Finch C. A new framework for research leading to sports injury prevention. J Sci Med Sport 2006;9:3-9.

23. Bergeron MF, Mountjoy M, Armstrong N, et al. International olympic committee consensus statement on youth athletic development. $\mathrm{Br}$ J Sports Med 2015;49:843-51.

24. Kontos AP. Perceived risk, risk taking, estimation of ability and injury among adolescent sport participants. J Pediatr Psychol 2004;29:447-55. 